\title{
Maternal complications and the utilisation of maternal health care services with special reference to West Bengal, India
}

\author{
Dipika Subba \\ Jawaharlal Nehru University, New Delhi, India \\ Email: subba.dipika@gmail.com \\ Received 16 May 2013; revised 14 June 2013; accepted 22 June 2013 \\ Copyright (C) 2013 Dipika Subba. This is an open access article distributed under the Creative Commons Attribution License, which \\ permits unrestricted use, distribution, and reproduction in any medium, provided the original work is properly cited.
}

\begin{abstract}
The study aims to examine maternal complications in the eastern states of India. Further, an attempt is also made to understand the socioeconomic factors that determine the utilization of health care services during maternity in the state of West Bengal. The data used for the study are District Level Household Survey (DLHS) 2007-08, which reveals wide regional variations in maternal complications in India. But the state of West Bengal depicts a unique picture. It has the dubious distinction of achieving low fertility and mortality with high maternal complications. The utilisation of health care services in West Bengal was never near completion. Full utilisation of ANC which is essential for safe motherhood is just above national average. A large number of deliveries still take place out of the institution and are unsafe. Analysis reveals that higher age at motherhood increases the probability of utilising maternal health care services. Social groups, years of schooling, wealth index and place of residence also show significant relationship. The findings of the study provide an insight that efforts should be made to create awareness among socially and economically disadvantaged groups of the society about the benefits of utilisation of health care services. Further it also addresses the issue of creating awareness about MDG's.
\end{abstract}

Keywords: Maternal Complications; Utilization of Maternal Health Care Services

\section{INTRODUCTION}

Globally, maternal mortality is the leading cause of death among women in the reproductive age. It is the consequence of pregnancy and childbirth or the consequence of utilisation of health care services during pregnancy and childbirth. Utilization of maternal health care services is a proximate determinant of maternal morbidities and mortalities [1,2]. It is of paramount importance as it affects the well-being of the mother as well as her children. Several studies have shown that the majority of maternal deaths can be prevented through early and timely access to and utilization of quality maternal health care services [1,3]. But implementing and assuring utilization of effective maternity care for women in the developing world is not an easy task. Since, late 80's improvement on maternal health and reducing maternal mortality became an area of concern for several international summits and conferences. Government of India has also initiated many programs and policies to curb the maternal mortality in order to improve the health condition of women. The goal to improve the maternal health received further momentum from the UN Summit on MDGs in 2000. In India, the maternal mortality ratio dropped from 600 deaths per 100,000 live births in 1990 to 390 in 2000 and to 200 in 2010 [4]. Though the maternal mortality ratio has improved over time but to meet the UN Millennium Development Goal, India needs to achieve the Maternal Mortality Ratio of 109 by 2015. Another program, Reproductive and Child Health Programme, emphasizes the need for mothers to deliver babies in hygienic conditions under the supervision of skilled health professionals, but most women in India deliver their babies at home without professional help. DLHS III, 2007-08 estimates that out of total birth 52 percent were delivered at home and out of which only 5 percent were assisted by a skilled person.

\section{STUDY AREA AND METHODOLOGY}

In the present study, the eastern region of India is taken into consideration. This region consists of the states of 
Bihar, Jharkhand, West Bengal and Odisha. It has a high density of 625 persons per square km (2011 census). Demographically, a large percentage of women in eastern states get married before the legal age of 18 years set by the government. Further, the large percent of women (56.6 percent) in the eastern states are illiterate [5]. The highest proportion of households in the lowest wealth quintile is observed. Very high TFR of 4 and 3.3 in 200506 is observed in Bihar and Jharkhand. Except for the state of West Bengal the infant and child mortality is also very high in all eastern states [6]. The maternal complications is very high in the eastern region. Eastern region alone accounts 25 percent of total maternal complications. Bihar has the highest maternal complications in India followed by Jharkhand in second place and West Bengal in third place.

Further the three states i.e. Bihar, Jharkhand and Odisha falls under Empowered Action Group States and has already been an area of concern in many studies. So for further micro study only West Bengal has been considered. It shows a unique picture. It has the dubious distinction of achieving low fertility and mortality along with high maternal complications. The level of infant mortality, maternal mortality and fertility are well below the respective national average. West Bengal has already achieved the replacement level of fertility with an average of 1.9 children in her lifetime (SRS 2008). It is also worth noting that the state of West Bengal has reached close to the target set by Millennium Development Goals of the United Nations of achieving Maternal Mortality Ratio of 109 per lakh live births by 2015. Age at marriage, educational level, use of antenatal care services have also increased over the period of time. But despite all these improved indicators the maternal complications in West Bengal are very high and rank $3^{\text {rd }}$ in India just after Bihar and Jharkhand. Thus in this context, the present study aims to examine the level of prevalence of maternal complications in eastern states. Further it aims to look at the utilisation of health care services and finally aims to examine the influence of socioeconomic factors on utilisation of health care services by currently married women in the selected state of West Bengal.

The study is based on District Level Household Survey 3 [5]. For the selected state West Bengal a total of 21,878 ever married women aged 15 - 49 years were interviewed. Out of these ever married women, 20,542 currently married women were selected for the present study. The method used in the study is logistic regression. For logistic regression, the dependent variables i.e. full ANC, safe delivery, institutional delivery and postnatal care have been categorised into 0 and 1 . The " 0 " category represents those women who did not seek any health care service and " 1 " represent those women who had sought any health care services.

\section{MATERNAL COMPLICATIONS IN EASTERN STATES}

In all the eastern states, maternal complications are above the national average of 80.2 percent (Table 1). In India at an average around 58 percent of women experience at least one pregnancy complications, 61 percent any delivery complications and 36 percent any post-delivery complications. The highest maternal complications were observed in Bihar (93.3 percent) followed by Jharkhand (92.2 percent) and West Bengal (91 percent). In case of pregnancy and post-delivery complications, Bihar has the highest complications with 75 percent and 57 percent respectively. Similarly in case of delivery complications Jharkhand experience highest complications with 83 percent followed by Bihar with 81 percent.

Large percentage of women in all the eastern states and more than half of the women in Bihar and West Bengal had reported paleness/giddiness/weakness as pregnancy complications. The reporting of excessive fatigue and swelling of hand, feet and face were also high. Reporting of excessive vomiting was also high in eastern states, with 27.9 percent highest in West Bengal. Excessive bleeding and virginal discharge are the low reported complications in all the eastern states. Obstructed labour, premature labour and prolonged labour are the main delivery complications. Beside these main complications, other complications which also add up to delivery complications are excessive bleeding, breech complication, convulsion and others. Obstructed complication had emerged out as very high reported complication by the women in all the eastern states with 65 percent highest in Bihar and Jharkhand. Breech presentation and Convulsion remained poorly reported complications by the women in all the eastern states because the breech presentations can be identified only through sonography and the percentage of sonography conducted in the eastern states is 16.8 percent against 35.6 percent of the national average. In case of post-delivery complications all the eastern states except Odisha have complications above national average. The incidence of post-delivery complications is judged by anyone with "high fever", "lower abdominal pain”, "foul smelling vaginal discharge”, and "excessive bleeding" during the first six weeks of delivery. Lower abdominal pain, high fever and severe headache are frequently reported complications among women. Lower abdominal pain was the highest complication reported in all the eastern states with 36.3 percent highest in Bihar. Convulsion and foul discharge are two complications which remained poorly reported by the women of eastern states.

The analysis of Table $\mathbf{1}$ clearly indicates that the three eastern states i.e. Bihar, Jharkhand and West Bengal have complications above national average. Further, in all the 
Table 1. Percentage of currently married women (15 - 49) who had complications during pregnancy, delivery and post-delivery, eastern states, 2007-08.

\begin{tabular}{|c|c|c|c|c|c|}
\hline Complications & Bihar & $\begin{array}{l}\text { West } \\
\text { bengal }\end{array}$ & Jharkhand & Odisha & India \\
\hline & \multicolumn{5}{|c|}{ Pregnancy Complications } \\
\hline $\begin{array}{l}\text { Swelling of hands, } \\
\text { feet and face }\end{array}$ & 28.3 & 25 & 29.4 & 27.2 & 24 \\
\hline $\begin{array}{l}\text { Paleness/giddiness/ } \\
\text { weakness }\end{array}$ & 56.7 & 51.6 & 44.8 & 35.7 & 35 \\
\hline Visual disturbances & 23.6 & 15 & 24.3 & 15.5 & 13.6 \\
\hline Excessive fatigue & 31.6 & 27.2 & 36.3 & 22.7 & 24.4 \\
\hline $\begin{array}{l}\text { Convulsion not } \\
\text { form fever }\end{array}$ & 7.8 & 3.1 & 11.4 & 8.1 & 6.5 \\
\hline $\begin{array}{l}\text { Weak or no movement } \\
\text { of foetus }\end{array}$ & 11 & 3.7 & 21 & 9.2 & 7.7 \\
\hline $\begin{array}{l}\text { Abnormal position } \\
\text { of foetus }\end{array}$ & 2.4 & 1.9 & 4.3 & 2.7 & 2.8 \\
\hline Excessive vomiting & 27.8 & 27.9 & 19.2 & 26.5 & 23.3 \\
\hline Excessive bleeding & 1.4 & 1.7 & 1.8 & 1.8 & 1.7 \\
\hline Virginal discharge & 3.3 & 5.2 & 2.4 & 1.8 & 3.2 \\
\hline Others & 2.8 & 5.8 & 1 & 0.9 & 1.8 \\
\hline \multirow[t]{2}{*}{ Any complication } & 75.4 & 70.8 & 66.1 & 58.5 & 57.8 \\
\hline & \multicolumn{5}{|c|}{ Delivery Complications } \\
\hline Premature labour & 35.3 & 31.6 & 51.5 & 40.6 & 29.7 \\
\hline Excessive bleeding & 8.5 & 11.8 & 16.5 & 14.2 & 9.1 \\
\hline Prolonged labour & 30.1 & 28.4 & 30.2 & 26 & 20.8 \\
\hline Obstructed labour & 65.7 & 53.5 & 65.7 & 43.8 & 42 \\
\hline Breech presentation & 4.6 & 4.1 & 7.7 & 4.2 & 5 \\
\hline Convulsion & 5.8 & 3.9 & 12 & 4.3 & 4.8 \\
\hline Other & 1 & 2.3 & 0.6 & 0.3 & 0.9 \\
\hline \multirow[t]{2}{*}{ Any complication } & 81.3 & 73.1 & 83.5 & 68.8 & 61.1 \\
\hline & \multicolumn{5}{|c|}{ Post-delivery Complications } \\
\hline High fever & 35 & 19.7 & 25.3 & 18.8 & 20.2 \\
\hline Lower abdominal pain & 36.3 & 28.7 & 29.3 & 16.2 & 20.8 \\
\hline $\begin{array}{c}\text { Foul smelling } \\
\text { vaginal discharge }\end{array}$ & 14.1 & 11.1 & 13.6 & 3.3 & 6.9 \\
\hline Excessive bleeding & 11.3 & 13.5 & 11.1 & 8.1 & 8.1 \\
\hline Convulsion & 7.6 & 1.8 & 8.3 & 6.3 & 4.3 \\
\hline Severe headache & 27.8 & 20.9 & 23 & 13.9 & 16.7 \\
\hline Other & 2.7 & 4.3 & 1.5 & 1.4 & 1.6 \\
\hline Any complications & 57.4 & 45.9 & 46.7 & 33 & 36.8 \\
\hline $\begin{array}{l}\text { Any complications } \\
\text { during maternity }\end{array}$ & 93.3 & 91 & 92.2 & 82.8 & 80.2 \\
\hline
\end{tabular}

Source: Unpublished work from dissertation based on DLHS 3 [7]. eastern states, similar reporting of complications was observed. The highest reporting was found on those complications which were easy to identify and can mention without any hesitation or awkwardness. Contrastingly, the health problems that carry a sense of shyness and strict medical examination were poorly reported.

In order to provide better interpretation of findings, background characteristics of currently married women has also been discussed (Table 2). It was observed that the age of consummation of marriage in all the eastern states except Odisha is very low. Around 39 percent of women in Bihar and 18 percent in West Bengal get married before 15 years of age. The distribution of the women based on age at first birth shows that in all the eastern states except Odisha, age of motherhood is very low. Around 60 percent women in West Bengal, 57 percent in Bihar and 52 percent in Jharkhand give birth to their first child at 15 - 19 years of age. West Bengal and Odisha are comparatively better in terms of birth order. Here almost 40 percent of currently married women have single birth. But in the states of Bihar and Jharkhand large percentage of women i.e. 39.7 percent and 31.3 percent have above 4 births. In all the eastern states, Hinduism is the dominant religion. In case of caste groups, a large percentage of currently married women in Bihar, Jharkhand and Odisha are OBC whereas Jharkhand and Odisha have a considerable percentage of tribal women. In case of West Bengal large percentage of currently married women are of general caste followed by schedule caste. With regard to the educational level of women, West Bengal is far better than other eastern states. Large percentages of women around 60 percent in West Bengal are literates. Unlike mother's years of schooling, the husband's years of schooling are comparatively better for all the eastern states. The distribution of currently married women by wealth quintiles also reveals that West Bengal is better compared to other eastern states. More the 30 percent of current married women fall in high wealth index as against 15 percent in Bihar and Jharkhand. Similarly large percentages of women (18.8 percent) in West Bengal reside in urban areas.

The background characteristics of currently married women in eastern states clearly indicate that the state of West Bengal is comparatively better than the other Eastern states. The state fairs in terms of the proportion literate (61 percent), proportion living in urban areas (19 percent), proportion in high wealth quintile (33 percent) and women with single birth (40 percent).

\section{UTILISATION OF MATERNAL HEALTH CARE SERVICES IN WEST BENGAL}

In West Bengal out of the total currently married women only one-fifth (Figure 1(a)) received full antenatal care. 
Table 2. Percentage distribution of currently married women at age 15 - 49 years by selected background characteristics, eastern states, 2007-08.

\begin{tabular}{|c|c|c|c|c|}
\hline Background & Bihar & Jharkhand & West Bengal & Odisha \\
\hline characteristics & $\%$ & $\%$ & $\%$ & $\%$ \\
\hline $\begin{array}{l}\text { Age at marriage } \\
\text { (below 15) }\end{array}$ & 38.8 & 16.1 & 18 & 6 \\
\hline $15-17$ & 37.6 & 39.5 & 41.4 & 36.4 \\
\hline $18^{+}$ & 23.6 & 44.5 & 40.7 & 57.6 \\
\hline $\begin{array}{l}\text { Age of women at birth } \\
\text { (below 15) }\end{array}$ & 1.4 & 1.7 & 3.3 & 0.8 \\
\hline $15-19$ & 56.9 & 52.4 & 60.2 & 45.4 \\
\hline $20-24$ & 37 & 38.5 & 30.3 & 43.8 \\
\hline $25^{+}$ & 4.7 & 7.4 & 6.2 & 10 \\
\hline Birth order (1) & 21.7 & 26 & 38.7 & 40 \\
\hline 2 & 20.5 & 23.6 & 31 & 26.9 \\
\hline 3 & 18.1 & 19.1 & 15.3 & 14.5 \\
\hline $4+$ & 39.7 & 31.3 & 15 & 18.6 \\
\hline Religion (Hindu) & 86.7 & 69.1 & 74.2 & 96 \\
\hline Muslim & 13.1 & 10.2 & 24.1 & 1 \\
\hline Others & 0.2 & 20.7 & 1.6 & 2.9 \\
\hline Caste (SC) & 20.5 & 14 & 34.7 & 20 \\
\hline ST & 2.1 & 32.5 & 8.7 & 27.5 \\
\hline OBC & 59.3 & 42.6 & 11.7 & 29.2 \\
\hline Others & 18.2 & 10.9 & 45 & 23.3 \\
\hline $\begin{array}{l}\text { Mother's Years of } \\
\text { Schooling (illiterate) }\end{array}$ & 65.9 & 63.1 & 39 & 46.1 \\
\hline $1-5$ & 11.8 & 11.3 & 24.4 & 19.9 \\
\hline $6-10$ & 18 & 20.5 & 29.7 & 27.1 \\
\hline Above 10 & 4.2 & 5 & 6.8 & 6.9 \\
\hline $\begin{array}{l}\text { Husband Years of } \\
\text { Schooling (illiterate) }\end{array}$ & 35.6 & 34.3 & 29.1 & 28 \\
\hline $1-5$ & 14.7 & 15.5 & 25.8 & 24.2 \\
\hline $6-10$ & 34 & 36.7 & 32.5 & 34 \\
\hline Above 10 & 15.8 & 13.5 & 12.6 & 13.7 \\
\hline Wealth Index (lowest) & 29.7 & 40.1 & 25.6 & 42.8 \\
\hline Second & 36.1 & 28.1 & 21.8 & 17.9 \\
\hline Middle & 17.9 & 13.5 & 20.3 & 15.3 \\
\hline Fourth & 10.9 & 9.5 & 19.1 & 13.4 \\
\hline Highest & 5.4 & 8.8 & 13.3 & 10.6 \\
\hline $\begin{array}{l}\text { Place of Residence } \\
\text { (Rural) }\end{array}$ & 91.3 & 86 & 81.1 & 87.5 \\
\hline Urban & 8.7 & 14 & 18.9 & 12.5 \\
\hline
\end{tabular}

Source: Unpublished work from dissertation based on DLHS 3 [7].
Similarly, in case of routine antenatal check-up it is observed that the check-up was never near completion. However, blood pressure, weight measure, hemoglobin test and abdomen checks were among the highest (Figure 1(b)). Antenatal advice was even poorer. Most of the women (more than 50 percent) received information regarding nutrition, breast feeding, institutional delivery and cleanliness (Figure 1(c)). It was also observed that a large percentage of women in West Bengal receive health care services from the government health center (81 percent) which is quite obvious because the private sector charges for antenatal services. Place of delivery (Figure 1(d)) shows that about half of the deliveries were conducted at home and the rest in different hospitals. Around 85 percent of deliveries (Figure 1(e)) were normal which is more common and only half of the deliveries (Figure 1(f)) were safe which include institutional delivery or home delivery assisted by a skilled person (i.e. Doctors, ANM, nurses and other health personnel). Though the proportion of institutional deliveries (49 percent) in West Bengal is much above the national average but the home delivery (50 percent) is higher than institutional delivery. Out of total institutional delivery 38.3 percent was conducted at public sector and only 10.8 percent at private sectors. While stating the reason behind not availing the institution for delivery, it appeared that 40 percent did not find that as necessary and 31 percent did not get time to go.

\section{RESULTS}

To examine the impact of the set of all variables, multi variant technique has been applied. Table 3 presents odd ratio of multivariate logistic regression for the four indicators of utilisation of maternal health care services i.e. full antenatal care, safe delivery, place of delivery and post-natal care. The odds ratio for each variable indicates the effect of that variable after controlling for each of the variables included in the regression analysis.

The age at marriage does not hold a significant relation with full antenatal care, safe delivery and place of delivery but has a significant relation with post-natal care. The women with higher age at marriage are more likely to seek post-natal care. Birth order of a child also shows a significant relation with the utilisation of all health care services (i.e. Full ANC, Safe delivery, Institutional delivery and postnatal care). With the increase in the birth order there is a decrease in utilisation of maternal health care services. Compared to 1st birth order, women with 2 - 3 birth order and above 4 are less likely to have a full antenatal care, safe delivery, institutional delivery and post-natal care. Social groups also show a significant relation with maternal health care use. Muslim women are 39 percent, 66 percent, 67 percent and 25 percent less likely to have full ANC, safe delivery, institutional de- 


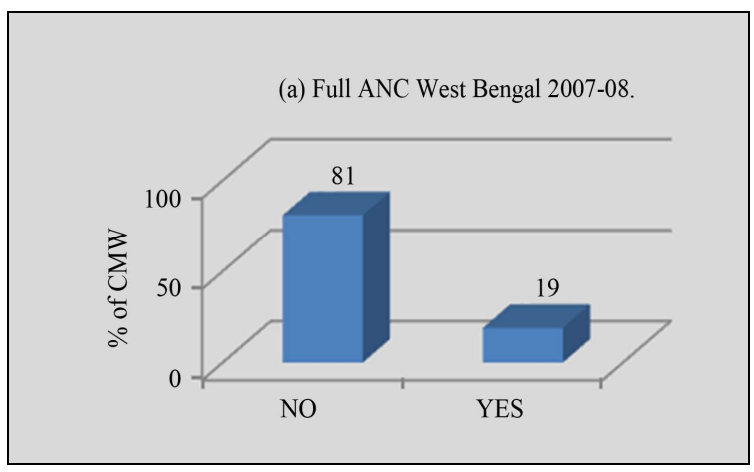

(c) Advice received on different component during ANC West Bengal, 2007-08.

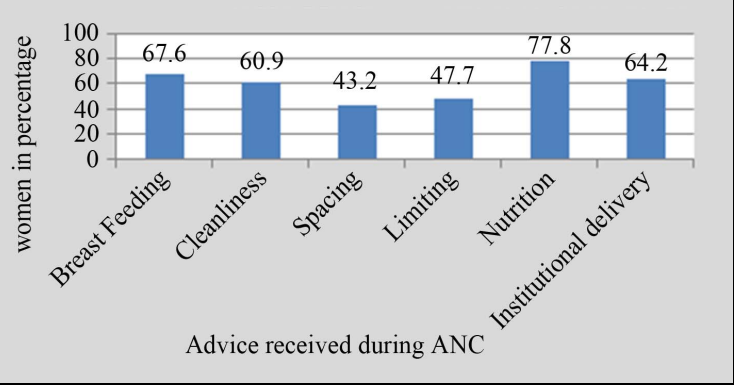

(e) Type of delivery West Bengal, 2007-08.

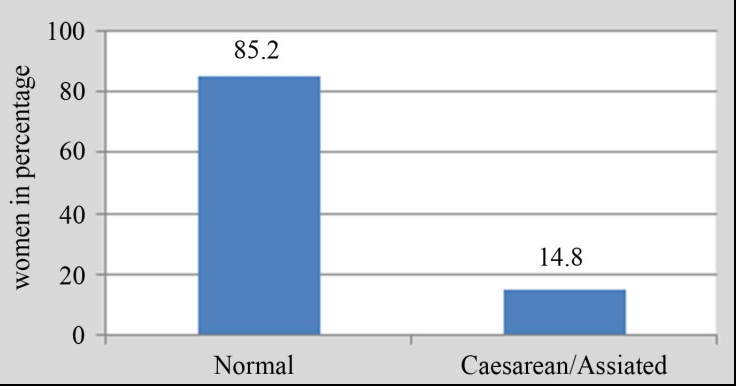

Source: Unpublished work from dissertation based on DLHS 3 [7].
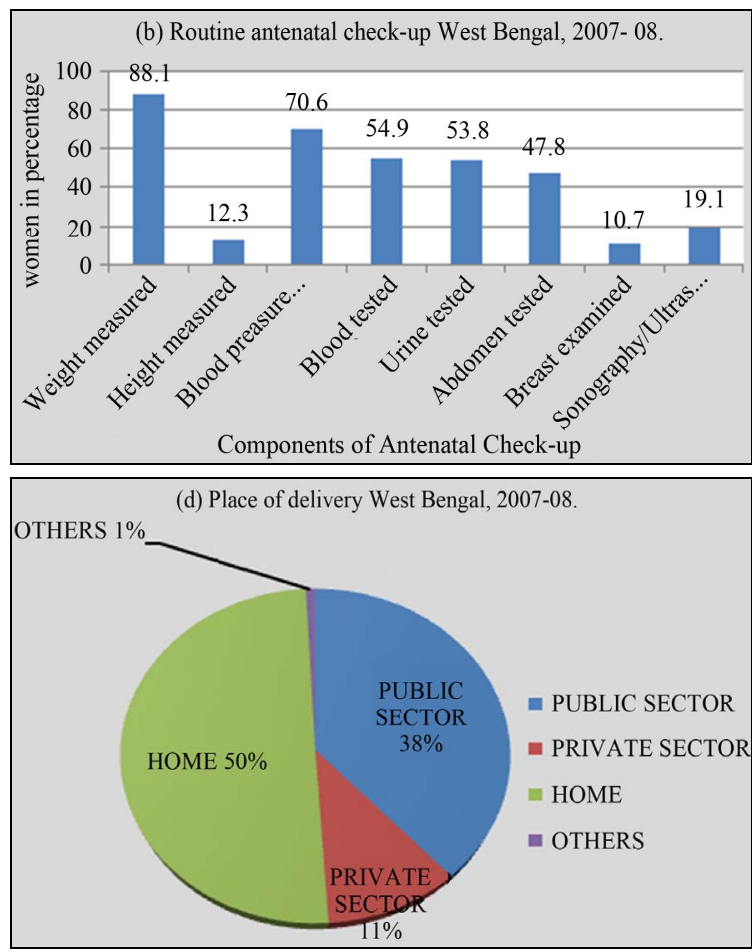

(f) Safe delivery West Bengal, 2007-08

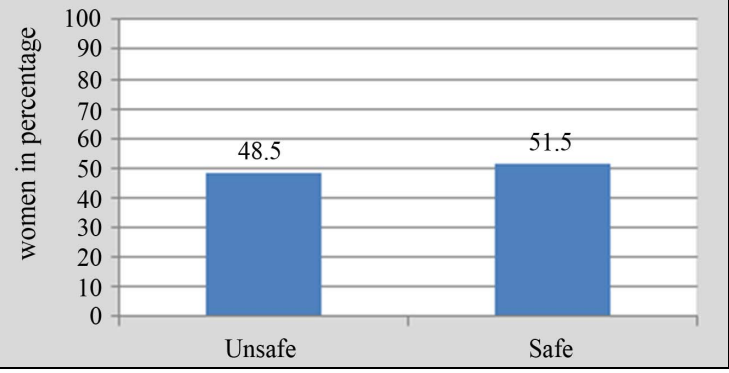

Figure 1. Utilisation of maternal health care services, eastern states (2007-08).

livery and post-natal care than Hindu women. In case of caste group, compared to General caste women, Schedule Caste and Schedule Tribe women have low chances of seeking health care services. Both mother's as well as husband's years of schooling have a significant influence on the utilisation of maternal health care services. There is an increase in the utilisation of maternal health services with the increase in years of schooling. Women who had completed above 10 years of schooling are 2 times more like to seek health care services than women who are illiterate. Husband's years of schooling also show that those husbands who have completed above 10 years of schooling are 57 percent, 68 percent and 43 percent more likely to go for full ANC, safe delivery, and institutional delivery. Wealth index, pregnancy wastage and place of residence also hold a significant relation with maternal health service use. The women in the higher wealth index are 7 times more likely to have a safe delivery and institutional delivery, 4 times more for post-natal care and 2 times more for full ANC. Similarly women with pregnancy wastage have higher probability to use maternal health care services. They are 47 percent, 50 percent and 45 percent more likely to have a safe delivery, institutional delivery and post-natal care than women who did not have any wastage. Urban women are also 2 times more likely to seek health care services than rural women.

\section{DISCUSSION}

The present study provides a better understanding to the level of prevalence of maternal complications in the Eastern States of India. It was observed that the complications which were easy to identify and can mention without any hesitation or awkwardness are the ones which were frequently reported, but in contrast to the 
Table 3. Odd ratios of logistic regression for the indicators of utilisation of maternal health care services.

\begin{tabular}{|c|c|c|c|c|}
\hline \multirow[t]{2}{*}{ Variables } & Full ANC & Safe Delivery & $\begin{array}{l}\text { Place of } \\
\text { Delivery }\end{array}$ & $\begin{array}{l}\text { Post Antal } \\
\text { Care }\end{array}$ \\
\hline & Exp (B) & $\operatorname{Exp}(B)$ & $\operatorname{Exp}(\mathrm{B})$ & $\operatorname{Exp}(B)$ \\
\hline \multicolumn{5}{|c|}{ Age at marriage: Ref. Below 15} \\
\hline $15-19$ & 0.9 & 1.04 & 1.11 & $1.26^{* *}$ \\
\hline $20-24$ & 0.86 & 1.14 & 1.21 & $1.29^{*}$ \\
\hline $25+$ & 1.04 & 0.97 & 0.85 & 0.9 \\
\hline \multicolumn{5}{|c|}{ Age of women at birth: Ref. Below 15} \\
\hline $15-19$ & 1.11 & 0.71 & 0.67 & 0.79 \\
\hline $20-24$ & 1.38 & 0.75 & 0.74 & 0.8 \\
\hline $25+$ & 1.34 & 1.10 & 1.13 & 0.95 \\
\hline \multicolumn{5}{|c|}{ Birth order: Ref. Below 2} \\
\hline $2-3$ & $0.77^{* * *}$ & $0.37^{* * *}$ & $0.38^{* * * *}$ & $0.59^{* * *}$ \\
\hline $4+$ & $0.54^{* * *}$ & $0.22^{* * *}$ & $0.21^{* * *}$ & $0.44^{* * *}$ \\
\hline \multicolumn{5}{|c|}{ Religion: Ref. Hindu } \\
\hline Muslim & $0.61^{* * *}$ & $0.44^{* * *}$ & $0.43^{* * *}$ & $0.75^{* * *}$ \\
\hline Others & 0.96 & $0.44^{* *}$ & $0.41^{* * *}$ & $0.35^{* * *}$ \\
\hline \multicolumn{5}{|c|}{ Caste: Ref. General } \\
\hline SC & $0.83^{*}$ & $0.73^{* * *}$ & $0.78^{* *}$ & 0.89 \\
\hline ST & 0.93 & $0.46^{* * *}$ & $0.49^{* * * *}$ & $0.53^{* * *}$ \\
\hline OBC & 0.9 & 1.1 & 1 & 0.83 \\
\hline \multicolumn{5}{|c|}{ Mother's year of school: Ref. Illiterate } \\
\hline Primary & 1.26 & $1.24^{* *}$ & $1.24^{* *}$ & 0.98 \\
\hline $\begin{array}{l}\text { Middle and } \\
\text { Secondary }\end{array}$ & $1.52^{* * *}$ & $1.56^{* * *}$ & $1.61^{* * *}$ & 1.1 \\
\hline $\begin{array}{c}\text { Above } \\
\text { Secondary }\end{array}$ & $2.08^{* * *}$ & $2.76^{* * *}$ & $2.89^{* * *}$ & $1.60^{* *}$ \\
\hline \multicolumn{5}{|c|}{ Husband years of schooling: Ref. Illiterate } \\
\hline Primary & $1.24^{*}$ & 1 & 0.98 & 1.05 \\
\hline $\begin{array}{l}\text { Middle and } \\
\text { Secondary }\end{array}$ & 1.10 & 1.14 & 1.08 & 1.14 \\
\hline $\begin{array}{c}\text { Above } \\
\text { Secondary }\end{array}$ & $1.57^{* * *}$ & $1.68^{* * * *}$ & $1.43^{* *}$ & 1.31 \\
\hline \multicolumn{5}{|c|}{ Wealth index: Ref. Lowest } \\
\hline Second & 1.12 & $1.26^{* *}$ & $1.30^{* * *}$ & $1.30^{* * *}$ \\
\hline Middle & $1.41^{* * *}$ & $1.43^{* * *}$ & $1.48^{* * *}$ & $1.60^{* * *}$ \\
\hline Fourth & $1.58^{* * * *}$ & $3.30^{* * *}$ & $3.19^{* * * *}$ & $2.20^{* * * *}$ \\
\hline Highest & $2.08^{* * *}$ & $7.58^{* * *}$ & $7.64^{* * *}$ & $4.91^{* * *}$ \\
\hline \multicolumn{5}{|c|}{ Pregnancy wastage: Ref. No } \\
\hline Yes & 0.92 & $1.47^{* * *}$ & $1.50^{* * * *}$ & $1.45^{* * *}$ \\
\hline \multicolumn{5}{|c|}{ Place of residence: Ref. Rural } \\
\hline Urban & 0.96 & $2.80^{* * *}$ & $2.72^{* * *}$ & $1.69^{* * *}$ \\
\hline
\end{tabular}

complications which carry a sense of shyness, strict medical examination were poorly reported. The background characteristic of currently married women in eastern states clearly shows that the state of West Bengal is comparatively better than the other Eastern states. However the maternal complications are also very high. In case of utilisation of maternal health care services it was also observed that the routine antenatal care was never near completion. Antenatal advice is even poorer. Full utilisation of ANC which is essential for safe motherhood is just above national average. A large number of deliveries still take place out of the institution. Out of total institutional delivery 38.3 percent was conducted in public sector and only 10.8 percent in private sectors because the mean cost of delivery at public sector (Rs 2366) is much lower than (Rs 9625) private sector [5]. Since the last 2 decades, the Government of India have taken many steps to curb the maternal mortality to improve the health condition of women. One of the major schemes was NRHM under which JSY has been implemented with an objective of full institutional deliveries by providing financial incentive for the mothers who choose institutional delivery. Though JSY is playing its role in providing cash assistance for institutional delivery but the cash assistance given to pregnant women during delivery is not enough to cover all expenses for institutional deliveries [8]. Around 51 percent of deliveries are taking place out of the institution attended mostly by the dais. Out of these non-institutional deliveries only 5 percent are safe. While stating the reason behind not availing the institution for delivery, it appeared that 40 percent did not find that as necessary and 31 percent did not get time to go.

The findings of the multi-variant logistic regression in the study suggest that age at marriage and age at motherhood do not hold any significant relation with full ANC, safe delivery and institution delivery but the age at motherhood has a significant influence on post-natal care which is similar to the finding observed in $[9,10]$. This may be due to the fact that the mother's age sometimes serves as a proxy for the women's accumulated knowledge of health care services which may have a positive influence on the use of health services [11]. Another demographic variable taken in this study is a birth order and the analysis revealed that women with higher birth order have low utilisation of health care services which is similar to the finding observed in $[9,11,12]$. As women are inexperienced with their $1^{\text {st }}$ pregnancy they give greater attention and seek more health care service and therefore less likely to seek health services with the increase in birth order [13]. Further, the study by Wong [14] also mentioned that having more children may also cause resource constraints, which have a negative effect on the utilisation of health care services. Socioeconomic vari- 
ables such as caste, religion, women year of schooling, husband's years of schooling and wealth index also reveal a significant relation with maternal health service use. In case of caste group, the finding shows a strong relation with the utilisation of health care service. SC/ST women are less likely to seek maternal health care services than general women, which is similar to the finding observed in $[13,15]$. This may be due to the fact that these SC/ST women are less educated and economically backward leading to less awareness of the availability of health care services and benefits in using them. In case of religion, Muslim women use less health care services compared to Hindu women because Muslim women have low education, low autonomy and rigid social custom [16, 17]. It was also observed that women and their husbands' years of schooling have a positive impact on utilisation of maternal health care services. Similar finding was observed in $[9,11,18]$ which may be due to the fact that better educated women are more aware of existing health care services and use them more effectively to maintain or achieve good health status. Further it is also argued that education also empowers women and provides greater confidence and capacity to make the decision to use modern health care services for them [19]. Wealth index which is used as a proxy indicator for standard of living indicates that with the increase in wealth index the likelihood of seeking health care services also increases. The similarly strong association between wealth index and utilisation of maternal health care services was found in the several studies. Women with pregnancy wastage seek more health care services, which is similar to the findings of [12]. Urban women are more likely to utilise maternal health care service than rural women. The low utilisation of maternal health services in rural areas may be due to strong traditional beliefs, low awareness of use of modern health services and poverty. It has also been mentioned in several studies that even if women are interested in checkups there are cost of transport and related services where a poor section of rural population cannot afford to pay. Further it has also been argued that women in rural areas usually find it difficult to travel to a health institution and feel uncomfortable to discuss their health problems if there is a male doctor.

The finding of the study suggests that in order to improve the utilisation of maternal health care services in West Bengal, effort has to be made to create awareness especially among women of rural area about the benefits of using health services. The analysis also highlights the fact that social position (caste) plays an important role in the utilisation of maternal health care services. The need for a target approach especially for schedule caste and tribe for improving the utilisation of maternal health services also needs to be realised. Further comprehensive efforts are also needed to target women of lower eco- nomic status with basic health care services. Thus, in order to achieve targets and goals set out by MDG's, effective policies should be implemented by focusing mainly on these disadvantaged groups.

\section{REFERENCES}

[1] Bhatia, J.C. and Cleland, J. (1993) Levels and causes of maternal mortality in south India. Studies in Family Planning, 24, 301-318. http://dx.doi.org/10.2307/2939224

[2] Mc. Carthy, J. and Maine, D. (1992) A framework for analyzing determinants of maternal mortality. Studied in Family Planning, 23, 23-33. http://dx.doi.org/10.2307/1966825

[3] Hauwa, S.A. (2011) Utilization of maternal health care services in Nigeria: An analysis of regional differences in the patterns and determinants of maternal health care use. Dissertation, University of Liverpool. http://success.ohecampus.com/files/pdfs/MPH/MPH_Qua ntitative_Dissertation_1.pdf

[4] Sexana, D.,Vangani, R., Mavalankar, D.V. and Thomsen, S. (2013) Inequity in maternal health care service utilizetion in Gujarat: Analysis of district level health survey data, Global Health Action, 6, 1-9.

[5] International Institute or Population Sciences (IIPS), (2005-2006) District level household and facility survey (DLHS-3), Mumbai.

[6] International Institute or Population Sciences (IIPS) and Macro International, (2007) National family health survey (NFHS-3), 2005-2006, Mumbai.

[7] Subba, D. (2013) Determinants of maternal complications in eastern states with special reference to West Bengal, India. M. Phill, Dissertation, Jawaharlal Nehru University, New Delhi.

[8] CORT (2007) Assessment of Janani Suraksha Yojana in West Bengal. http://www.cortindia.in/RP\%5CRP-2007-0503.pdf

[9] Elo, T.I. (1992) Utilisation of maternal health care services in peru, the role of women's education. Health Transition Review. Vol 2, 49-69.

[10] Fiedler, J.L. (1981) A review of the literature on access and utilisation of medical care with special emphasis on rural primary care. Social Science and Medicine. Vol 15, 129-142.

[11] Chakraborty, N., Islam, M.A., Chowdhury, R.I., Bari, W. and Akhtar, H. (2003) Determinants of the use of maternal health services in rural Bangladesh, Health Promotion International, 18, 327-337. http://dx.doi.org/10.1093/heapro/dag414

[12] Bhatia, J.C. and Cleland, J. (1995) Determinants of maternal care in a region of South India. Health Transition Review, 5, 127-142.

[13] Navaneetham, K. and Dharmalingam, A. (2002) Utilisation of maternal health care services in Southern India. Social Science and Medicine, 55, 1849-1869. http://dx.doi.org/10.1016/S0277-9536(01)00313-6 
[14] Wong, E.L., Popkin, B.M., Cullkey, D.K and Akin, J.S. (1987) Accessibility, quality of care and prenatal care use in the Philippines. Social Science and Medicine, 24, 927944. http://dx.doi.org/10.1016/0277-9536(87)90286-3

[15] Sontakke, P., Reshmi, R.S. and Sebastian, D. (2009) Obstetric morbidity among currently married women in selected states in India. Journal of Family Welfare, 55, 1726.

[16] Manna, P.K., De, D. and Ghosh, D. (2011) Knowledge attitude and practices for antenatal care and delivery of the mothers of tea garden in Jalpaiguri and Darjeeling Districts, West Bengal. National Journal of Community
Medicine, 2, 4-8.

[17] Salam, A. and Siddiqui, S. A. (2006) Socioeconomic inequalities in use of delivery care services in India. Journal of Obstetric Gynecology India, 56, 123-127.

[18] Becker, S., Peters, D.H., Gray, R.H., Gulatiano, C. and Blake R.E. (1998) Determinants of use of maternal and child health service in Cebu, the Phillippines. Health Transition Review, 3, 77-89.

[19] Mosley, W.H. and Chen, L.C. (1994) An analytical framework for the study of child survival in developing countries. Population and Development Review, 10, 2545. http://dx.doi.org/10.2307/2807954 